\title{
Impact of retrieved lymph node count on short-term complications in patients with gastric cancer
}

\author{
Feng Sun ${ }^{\dagger}$, Song Liu ${ }^{\dagger}$, Peng Song ${ }^{\dagger}$, Chen Zhang, Zhijian Liu, Wenxian Guan ${ }^{*}$ (D) and Meng Wang ${ }^{*}$
}

\begin{abstract}
Background: It is well established that retrieved lymph node (RLN) counts were positively correlated with better overall survival in gastric cancer (GC). But little is known about the relationship between RLN count and short-term complications after radical surgery.

Methods: A total of 1487 consecutive GC patients between January 2016 and December 2018 at Nanjing Drum Tower Hospital were retrospectively analyzed. Univariate analyses were performed to elucidate the association between RLN count and postoperative complications. We further identified clinical factors that might affect the RLN count.

Results: Among all of the patients, postoperative complications occurred in 435 (29.3\%) patients. The mean RLN count was 25.1, and 864 (58.1\%) patients were diagnosed with lymph node metastasis. Univariate analyses showed no significant difference between RLN count and postoperative complications (both overall and stratified by CDC grade). Univariate and multivariate analyses further revealed that type of resection, tumor invasion, and lymph node metastasis were associated with RLN count.

Conclusions: The current study demonstrated that RLN count was not associated with postoperative short-term complications following gastrectomy of GC, which provided a rationale for the determination of a proper RLN count of curative gastrectomy.
\end{abstract}

Keywords: Retrieved lymph nodes, Postoperative complications, Gastric cancer

\section{Background}

There are approximately one million new cases of gastric cancer (GC) each year worldwide, and half of them occur in Eastern Asia, including China, Japan, and South Korea [1]. Despite advances in early screening and comprehensive treatment of GC, it remains the third most common cause of cancer-related death in the world [2]. For advanced GC, a consensus has been reached of radical gastrectomy with D2 lymphadenectomy [3]. However, there

\footnotetext{
* Correspondence: medguanwenxian@163.com; wangmeng001@263.net ${ }^{\dagger}$ Feng Sun, Song Liu and Peng Song contributed equally to this work. Department of Gastrointestinal Surgery, Nanjing Drum Tower Hospital, The Affiliated Hospital of Nanjing University Medical School, Nanjing, China
}

is still controversy over the number of retrieved lymph nodes (RLNs) for accurate pathological staging.

Several studies have reported that RLN count was positively correlated with better overall survival in GC, even in lymph node-negative GC [4-7]. An RLN count of $\geq 16$ has been recommended by the 8th edition TNM classification for $\mathrm{GC}$ to guarantee the accurate $\mathrm{pN}$ stage [8]. Moreover, Okajima et al. suggested an optimal RLN count of $\geq 25$ for nodal staging [9]. Recently, by stratum analysis of 7620 patients, Deng et al. proposed an optimal RLN count of $\geq 16$ for lymph node-negative GC and $>30$ for lymph node-positive GC [10]. These above studies are all conducted by comparing the RLN count

(c) The Author(s). 2020 Open Access This article is licensed under a Creative Commons Attribution 4.0 International License, which permits use, sharing, adaptation, distribution and reproduction in any medium or format, as long as you give appropriate credit to the original author(s) and the source, provide a link to the Creative Commons licence, and indicate if changes were made. The images or other third party material in this article are included in the article's Creative Commons licence, unless indicated otherwise in a credit line to the material. If material is not included in the article's Creative Commons licence and your intended use is not permitted by statutory regulation or exceeds the permitted use, you will need to obtain permission directly from the copyright holder. To view a copy of this licence, visit http://creativecommons.org/licenses/by/4.0/ The Creative Commons Public Domain Dedication waiver (http://creativecommons.org/publicdomain/zero/1.0/) applies to the data made available in this article, unless otherwise stated in a credit line to the data. 
Table 1 Demographic and clinical features of patients

\begin{tabular}{|c|c|}
\hline Characteristics & $N=1487$ \\
\hline Age (years) & $60.4 \pm 17.3$ \\
\hline \multicolumn{2}{|l|}{ Gender $(n)$} \\
\hline Male & 1089 \\
\hline Female & 398 \\
\hline BMI $\left(\mathrm{kg} / \mathrm{m}^{2}\right)$ & $23.0 \pm 3.5$ \\
\hline \multicolumn{2}{|c|}{ Preoperative comorbidities ( $n$ ) } \\
\hline $\begin{array}{l}\text { Previous abdominal } \\
\text { surgery }\end{array}$ & 209 \\
\hline Diabetes mellitus & 131 \\
\hline Hypertension & 488 \\
\hline \multicolumn{2}{|c|}{ Preoperative laboratory data } \\
\hline Serum albumin (g/L) & $39.4 \pm 3.3$ \\
\hline CRP $(g / L)$ & $6.0 \pm 12.4$ \\
\hline$A S A \geq 3$ & 884 \\
\hline \multicolumn{2}{|c|}{ Mode of surgical approach (n) } \\
\hline Laparoscopic & 76 \\
\hline Open & 1411 \\
\hline \multicolumn{2}{|l|}{ Type of resection $(n)$} \\
\hline Distal gastrectomy & 617 \\
\hline Proximal gastrectomy & 163 \\
\hline Total gastrectomy & 707 \\
\hline Operation time (min) & $232.3 \pm 61.8$ \\
\hline Blood loss (ml) & $221.8 \pm 204.5$ \\
\hline \multicolumn{2}{|l|}{ Tumor invasion } \\
\hline $\mathrm{T} 1-2$ & 631 \\
\hline T3-4 & 856 \\
\hline \multicolumn{2}{|l|}{ Tumor site } \\
\hline Cardia/fundus & 452 \\
\hline Body & 381 \\
\hline Pylorus/antrum & 654 \\
\hline RLN count & $25.1 \pm 9.1$ \\
\hline \multicolumn{2}{|l|}{ Lymph node metastasis } \\
\hline Positive & 864 \\
\hline Negative & 623 \\
\hline LNR & $0.17 \pm 0.24$ \\
\hline LODDS & $-0.96 \pm 0.75$ \\
\hline pTNM stage I/II/III/IV & $506 / 368 / 597 / 16$ \\
\hline \multicolumn{2}{|l|}{ Lauren subtype } \\
\hline Intestinal & 620 \\
\hline Diffuse & 428 \\
\hline Mixed & 401 \\
\hline Unknown & 38 \\
\hline \multicolumn{2}{|c|}{ Postoperative complications } \\
\hline Positive & 435 \\
\hline
\end{tabular}

Table 1 Demographic and clinical features of patients (Continued)

\begin{tabular}{ll}
\hline Characteristics & $N=1487$ \\
\hline Negative & 1052 \\
Postoperative stay (days) & $12.0 \pm 8.1$ \\
Total hospital charges $\left(10^{4} ¥\right)$ & $7.5 \pm 3.5$ \\
\hline BMI body mass index, CRP C-reactive protein, ASA American Society of \\
Anesthesiologists, RLNs retrieved lymph nodes, LNR lymph node ratio, LODDS \\
log odds of positive lymph nodes
\end{tabular}

with long-term survival. But little is known about the relationship between the RLN count and short-term complications after radical surgery.

Postoperative complications of GC pose a significant impact on the length of postoperative stay and hospital charges, which further affect the quality of life [11]. Therefore, investigating the relationship between RLN count and postoperative short-term complications would provide more comprehensive evidence for selecting the appropriate RLN count.

\section{Methods \\ Patients}

A total of 1487 consecutive GC patients between January 2016 and December 2018 at Nanjing Drum Tower Hospital were retrospectively reviewed. All patients underwent curative (R0) gastrectomy and were histologically confirmed. The exclusion criteria were as follows: (1) multivisceral resection, (2) patients accepting preoperative radiotherapy or chemotherapy, (3) patients with previous stomach surgery, and (4) patients with incomplete clinical data. This study was approved by the Ethics Committee of Nanjing Drum Tower Hospital.

\section{Data collection}

Data for preoperative characteristics, intraoperative index, and postoperative features were extracted. Preoperative characteristics included age, gender, body mass index (BMI), comorbidities, and laboratory data. The intraoperative index involved the American Society of Anesthesiologists (ASA) grade, surgical approach, type of resection, operation time, and blood loss. Postoperative features included depth of tumor invasion, tumor site, retrieved lymph node count, lymph node metastasis, lymph node ratio (LNR), log odds of positive lymph nodes (LODDS), pTNM stage, Lauren subtype, short-term complications, postoperative stay, and total hospital charges. LNR was defined as the ratio of positive to retrieved lymph nodes. LODDS was calculated by $\log$ [(positive lymph nodes +0.5$) /($ total lymph nodes - positive lymph nodes +0.5$)$ ] [12]. The postoperative short-term complications occurring in the hospital or within 30 days were collected. All complications were evaluated according to the Clavien-Dindo classification system [13]. 


\section{Statistical analysis}

Statistical analyses were conducted by SPSS 19.0 (Chicago, IL, USA). Continuous variables were shown as means \pm SD. Student's $t$ test was applied for normally distributed data; Mann-Whitney $U$ test was applied for non-normally distributed data. Categorical variable data were presented as numbers and analyzed using the chisquared test or the Fisher exact test. Univariate and multivariate analyses were performed to analyze the risk factors associated with the postoperative complications or retrieved lymph node count. The optimal cutoff values of LNR and LODDS were determined by receiver

Table 2 Univariate and multivariate analyses of characteristics associated with postoperative complications

\begin{tabular}{|c|c|c|c|c|c|c|}
\hline \multirow[t]{2}{*}{ Characteristics } & \multicolumn{3}{|c|}{ Univariate } & \multicolumn{3}{|c|}{ Multivariate } \\
\hline & $\overline{\mathrm{OR}}$ & $95 \% \mathrm{Cl}$ & $P$ & $\overline{\mathrm{OR}}$ & $95 \% \mathrm{Cl}$ & $P$ \\
\hline Age $\geq 70$ & 1.581 & $1.232-2.029$ & $<0.001$ & 1.578 & $1.219-2.044$ & 0.001 \\
\hline \multicolumn{7}{|l|}{ Gender } \\
\hline Male & 0.765 & $0.597-0.979$ & 0.033 & 0.710 & $0.551-0.916$ & 0.008 \\
\hline \multicolumn{7}{|l|}{ Female } \\
\hline $\mathrm{BMI}\left(\mathrm{kg} / \mathrm{m}^{2}\right)$ & 0.988 & $0.956-1.020$ & 0.449 & & & \\
\hline \multicolumn{7}{|l|}{ Preoperative comorbidities } \\
\hline Previous abdominal surgery & 0.996 & $0.722-1.374$ & 0.982 & & & \\
\hline Diabetes mellitus & 1.156 & $0.787-1.700$ & 0.460 & & & \\
\hline Hypertension & 1.128 & $0.891-1.428$ & 0.317 & & & \\
\hline \multicolumn{7}{|l|}{ Preoperative laboratory data } \\
\hline Serum albumin $<35 \mathrm{~g} / \mathrm{L}$ & 1.660 & $1.162-2.372$ & 0.005 & 1.544 & $1.068-2.232$ & 0.021 \\
\hline $\mathrm{CRP} \geq 10 \mathrm{~g} / \mathrm{L}$ & 1.315 & $0.892-1.938$ & 0.167 & & & \\
\hline$A S A \geq 3$ & 1.047 & $0.834-1.315$ & 0.693 & & & \\
\hline \multicolumn{7}{|l|}{ Mode of surgical approach } \\
\hline Laparoscopic & 0.684 & $0.394-1.188$ & 0.178 & & & \\
\hline \multicolumn{7}{|l|}{ Open } \\
\hline Type of resection & & & 0.067 & & & 0.025 \\
\hline Total gastrectomy & & Reference & & & Reference & \\
\hline Distal gastrectomy & 1.183 & $0.932-1.503$ & 0.167 & 1.242 & $0.972-1.588$ & 0.083 \\
\hline Proximal gastrectomy & 1.503 & $1.047-2.157$ & 0.027 & 1.613 & $1.117-2.329$ & 0.011 \\
\hline Operation time & 1.002 & $1.001-1.004$ & 0.009 & 1.003 & $1.001-1.005$ & 0.002 \\
\hline Blood loss & 1.000 & $1.000-1.001$ & 0.094 & & & \\
\hline Tumor site & & & 0.780 & & & \\
\hline Cardia/fundus & & Reference & & & & \\
\hline Body & 1.054 & $0.811-1.370$ & 0.693 & & & \\
\hline Pylorus/antrum & 0.947 & $0.716-1.252$ & 0.701 & & & \\
\hline Tumor invasion (T3-4) & 1.216 & $0.968-1.527$ & 0.093 & & & \\
\hline RLNs & 0.991 & $0.979-1.004$ & 0.165 & & & \\
\hline Lymph node metastasis & 1.044 & $0.832-1.310$ & 0.707 & & & \\
\hline LNR $>0.05$ & 1.213 & $0.969-1.517$ & 0.091 & & & \\
\hline LODDS > - 1.1 & 1.219 & $0.975-1.525$ & 0.083 & & & \\
\hline pTNM stage ( $\geq$ III) & 1.036 & $0.826-1.300$ & 0.757 & & & \\
\hline Lauren subtype & & & 0.952 & & & \\
\hline Intestinal & & Reference & & & & \\
\hline Diffuse & 0.866 & $0.427-1.754$ & 0.689 & & & \\
\hline Mixed & 0.904 & $0.442-1.848$ & 0.782 & & & \\
\hline Unknown & 0.925 & $0.452-1.894$ & 0.832 & & & \\
\hline
\end{tabular}


operating characteristic (ROC) analysis. All statistical tests were conducted two-sided, and statistical differences were termed as $P$ value $<0.05$.

\section{Results}

\section{Patient characteristics}

The background characteristics of the patients enrolled in this study were presented in Table 1 . There were 1487 GC patients in all, including 1089 (73.2\%) men and $398(26.8 \%)$ women. The median age was 60 years with a range from 21 to 96 years. A total of 1411 (94.9\%) patients underwent open gastrectomy while 76 (5.1\%) underwent laparoscopic surgery. The type of resection was distal gastrectomy in $617(41.5 \%)$ patients, proximal gastrectomy in 163 (11.0\%), and total gastrectomy in 707 (47.5\%). The mean operation time was $232 \mathrm{~min}$, and the mean intraoperative blood loss was $221 \mathrm{ml}$. Pathological results were stage I/II/III/IV in 506/368/597/16 patients, respectively. The mean RLN count was 25.1 (range, 2$84)$, and $864(58.1 \%)$ patients were tested with lymph node metastasis. Overall, postoperative short-term complications occurred in $435(29.3 \%)$ patients. The mean postoperative stay was 12 days, and the mean total hospital charges were $7.5 \times 10^{4} ¥$.

\section{Association between perioperative characteristics and postoperative complications}

As presented in Table 2, univariate and multivariate analyses indicated that postoperative short-term complications were significantly correlated with age, gender, level of preoperative serum albumin, and operation time. Stratified analyses by type of resection revealed that complications occurred frequently in proximal gastrectomy compared with total gastrectomy, while there was no significant difference between distal gastrectomy and total gastrectomy. No significant association was observed between RLN count and overall postoperative complications.

\section{Impact of RLN count on postoperative complications}

Of the 1487 patients, 435 (29.3\%) developed complications: $74 \%$ (323 of 435) encountered a single complication, and 26\% (112 of 435) encountered multiple complications. The details of patients with short-term complications based on the Clavien-Dindo classification are $15.5 \%$ for grade I, $9.2 \%$ for grade II, $4.0 \%$ for grade III, $0.3 \%$ for grade IV, and $0.2 \%$ for grade $\mathrm{V}$. The rate of major complications (CDC grade $\geq$ III) was $4.5 \%$. The median RLN count in this study was 24. So, we divided all patients into two groups based on the median RLN count. Univariate analyses showed no significant difference between RLN count and postoperative complications (both overall and stratified by CDC grade) (Table 3 ).
Table 3 Univariate analyses of postoperative complications associated with RLN count

\begin{tabular}{|c|c|c|c|c|}
\hline \multirow[t]{2}{*}{ Characteristics } & \multirow[t]{2}{*}{ All } & \multicolumn{2}{|c|}{ RLN count } & \multirow{2}{*}{$\begin{array}{l}P \\
\text { value }\end{array}$} \\
\hline & & $<25$ & $\geq 25$ & \\
\hline Overall $(n)$ & 435 & 248 & 187 & 0.062 \\
\hline Grade I (n) & 231 & 132 & 99 & 0.198 \\
\hline Fever $>37.5^{\circ} \mathrm{C}$ & 144 & 85 & 59 & \\
\hline Emesis & 156 & 83 & 73 & \\
\hline Pain & 30 & 18 & 12 & \\
\hline Abdominopelvic collection & 1 & 1 & 0 & \\
\hline Pleural effusion & 4 & 4 & 0 & \\
\hline Grade II (n) & 137 & 78 & 59 & 0.366 \\
\hline Blood transfusions & 60 & 38 & 22 & \\
\hline Early postoperative bowel obstruction & 2 & 1 & 1 & \\
\hline Gastroparesis & 25 & 14 & 11 & \\
\hline Liver function abnormalities & 1 & 1 & 0 & \\
\hline Wound infection & 8 & 5 & 3 & \\
\hline Pneumonia & 27 & 15 & 12 & \\
\hline Intra-abdominal infections & 20 & 12 & 8 & \\
\hline Urinary tract infection & 4 & 0 & 4 & \\
\hline Enteritis & 3 & 1 & 2 & \\
\hline Bacteremia & 14 & 7 & 7 & \\
\hline Grade III (n) & 59 & 32 & 27 & 0.878 \\
\hline Anastomotic leakage & 23 & 14 & 9 & \\
\hline Lymphatic leakage & 8 & 3 & 5 & \\
\hline Pancreatic fistula & 2 & 0 & 2 & \\
\hline Biliary fistula & 1 & 0 & 1 & \\
\hline Bleeding & 8 & 5 & 3 & \\
\hline Abdominopelvic collection & 1 & 1 & 0 & \\
\hline Pleural effusion & 9 & 5 & 4 & \\
\hline Intra-abdominal abscess & 2 & 1 & 1 & \\
\hline Wound disruption & 3 & 3 & 0 & \\
\hline Delayed wound healing & 4 & 3 & 1 & \\
\hline Gastroparesis & 1 & 0 & 1 & \\
\hline Early postoperative bowel obstruction & 1 & 0 & 1 & \\
\hline Splenic necrosis & 1 & 0 & 1 & \\
\hline Grade IV $(n)$ & 5 & 4 & 1 & 0.452 \\
\hline Heart failure & 1 & 1 & 0 & \\
\hline Kidney failure & 1 & 1 & 0 & \\
\hline Brain infarction & 1 & 0 & 1 & \\
\hline MODS & 2 & 2 & 0 & \\
\hline Grade $V(n)$ & 3 & 2 & 1 & 1.000 \\
\hline Grade $\geq \| I(n)$ & 67 & 38 & 29 & 0.562 \\
\hline
\end{tabular}

RLNs retrieved lymph nodes, MODS multiple organ dysfunction syndrome 


\section{Factors associated with RLN count}

We further explored the potential factors associated with RLN count. Univariate analyses revealed that preoperative serum albumin, type of resection, tumor invasion, lymph node metastasis, and pTNM stage were associated with RLN count $(P<0.05$; Table 4$)$. Stratification by type of resection showed that RLN count in either distal gastrectomy or proximal gastrectomy was significantly lower than that in total gastrectomy. Multivariate analyses further indicated that type of resection, tumor invasion, and lymph node metastasis were still significantly associated with RLN count $(P<0.05$; Table 4$)$.

\section{Discussion}

Nodal involvement significantly affected the prognosis of GC patients because it is the major root of tumor relapse after surgery $[14,15]$. Thus, standardized lymph node dissection is the basic requirement for curative

Table 4 Univariate and multivariate analyses of factors associated with RLN count $\geq 25$

\begin{tabular}{|c|c|c|c|c|c|c|}
\hline \multirow[t]{2}{*}{ Characteristics } & \multicolumn{3}{|c|}{ Univariate } & \multicolumn{3}{|c|}{ Multivariate } \\
\hline & $\mathrm{OR}$ & $95 \% \mathrm{Cl}$ & $P$ & $\mathrm{OR}$ & $95 \% \mathrm{Cl}$ & $P$ \\
\hline Age $\geq 70$ & 0.873 & $0.689-1.105$ & 0.259 & & & \\
\hline \multicolumn{7}{|l|}{ Gender } \\
\hline Male & 1.043 & $0.828-1.312$ & 0.723 & & & \\
\hline \multicolumn{7}{|l|}{ Female } \\
\hline BMI $\left(k g / m^{2}\right)$ & 0.972 & $0.944-1.002$ & 0.064 & & & \\
\hline \multicolumn{7}{|l|}{ Preoperative comorbidities } \\
\hline Previous abdominal surgery & 1.030 & $0.768-1.380$ & 0.844 & & & \\
\hline Diabetes mellitus & 0.960 & $0.670-1.375$ & 0.822 & & & \\
\hline Hypertension & 0.852 & $0.685-1.059$ & 0.148 & & & \\
\hline \multicolumn{7}{|l|}{ Preoperative laboratory data } \\
\hline Serum albumin < $35 \mathrm{~g} / \mathrm{L}$ & 1.484 & $1.048-2.102$ & 0.026 & & & \\
\hline$C R P \geq 10 \mathrm{~g} / \mathrm{L}$ & 1.195 & $0.827-1.726$ & 0.343 & & & \\
\hline$A S A \geq 3$ & 0.892 & $0.725-1.098$ & 0.282 & & & \\
\hline \multicolumn{7}{|l|}{ Mode of surgical approach } \\
\hline Laparoscopic & 1.282 & $0.808-2.036$ & 0.292 & & & \\
\hline \multicolumn{7}{|l|}{ Open } \\
\hline Type of resection & & & $<0.001$ & & & $<0.001$ \\
\hline Total gastrectomy & & Reference & & & Reference & \\
\hline Distal gastrectomy & 0.649 & $0.522-0.807$ & $<0.001$ & 0.716 & $0.572-0.896$ & 0.004 \\
\hline Proximal gastrectomy & 0.334 & $0.231-0.485$ & $<0.001$ & 0.357 & $0.245-0.519$ & $<0.001$ \\
\hline Operation time & 1.001 & $1.000-1.003$ & 0.086 & & & \\
\hline Blood loss & 1.000 & $1.000-1.001$ & 0.482 & & & \\
\hline Tumor site & & & 0.304 & & & \\
\hline Cardia/fundus & & Reference & & & & \\
\hline Body & 0.903 & $0.709-1.148$ & 0.404 & & & \\
\hline Pylorus/antrum & 1.119 & $0.869-1.442$ & 0.382 & & & \\
\hline Tumor invasion (T3-4) & 1.613 & $1.310-1.987$ & $<0.001$ & 1.299 & $1.010-1.670$ & 0.042 \\
\hline Lymph node metastasis & 1.585 & $1.286-1.952$ & $<0.001$ & 1.304 & $1.018-1.669$ & 0.035 \\
\hline pTNM stage ( $\geq$ III) & 1.555 & $1.263-1.914$ & $<0.001$ & & & \\
\hline Lauren subtype & & & 0.082 & & & \\
\hline Intestinal & & Reference & & & & \\
\hline Diffuse & 1.040 & $0.536-2.019$ & 0.908 & & & \\
\hline Mixed & 1.388 & $0.709-2.716$ & 0.339 & & & \\
\hline Unknown & 1.328 & $0.677-2.603$ & 0.409 & & & \\
\hline
\end{tabular}


(R0) gastrectomy. Curative gastrectomy with D2 lymphadenectomy has been considered as the standard fashion for decades in Eastern Asia, especially in Japan [16, 17]. This procedure has been gradually accepted by Western countries in recent years $[18,19]$. As for the RLN count, the 8th edition TNM classification for GC recommended dissecting at least 16 lymph nodes. Moreover, emerging evidence revealed the positive correlations between RLN count and overall survival of GC patients [4, 5, 20]. By comparing RLN count to survival time, Okajima et al. suggested an optimal RLN count of $\geq 25$ [9]; Deng et al. proposed an optimal RLN count of $\geq 16$ for lymph node-negative GC and > 30 for lymph node-positive GC by stratum analysis of 7620 patients [10]; Sano et al. reported that RLN count preferably achieved 30 or more by a multicenter study enrolling 25,411 patients [20]. Additionally, LNR and LODDS were also reported to be associated with GC prognosis [21-23]. These above studies mainly focused on the relationship between RLN count and long-term prognosis. However, little is known about its effects on postoperative short-term complications.

In this study, we concentrated on the association between RLN count and short-term prognosis. Univariate analyses showed no significant difference between RLN count and postoperative complications (both overall and stratified by CDC grade). Therefore, more lymph nodes were encouraged to be dissected from the perspective of short-term prognosis.

Although curative gastrectomy with D2 lymphadenectomy is considered a pivotal strategy for advanced GC, there are international and institutional differences in the number of RLN count [24, 25]. Various factors were reported to influence the RLN count, including the confidence and enthusiasm of doctors (both surgeons and pathologists), surgical situation, and innate lymph node count in each patient $[7,9]$. In our study, we concluded that RLN count was related to the type of resection, tumor invasion, and lymph node metastasis. Of note, RLN count was positively correlated with the lymph node metastasis rate, which underlined the importance of RLN count for accurate staging.

Actually, for a thorough pathological examination, RLNs should be individually divided from a complete tissue sample after surgery. Owing to much time and effort was required during this procedure, it has not been widely implemented clinically. Therefore, the examined lymph node count by pathologists might be lower than the dissected lymph node count. Multiple attempts have been conducted to improve the detection rate of lymph nodes [26-28]. Li et al. elucidated that the mean number of RLNs could be significantly elevated by injecting carbon nanoparticles before surgery compared with controls (38.33 vs 28.27) [26]. Markl and colleagues reported a twofold lymph node pick up rate utilizing methylene blue staining than unstained groups (35 vs 17) [27]. Several dye materials were also used to increase the number of lymph nodes dissected during surgery, such as fluorescent indocyanine green (ICG) and 5-aminolevulinic acid (5-ALA) [29, 30].

We acknowledge that this study had some potential limitations. First, it was a retrospective, single-center study, so the results might be flawed because of residual confounding factors. Second, the RLN count was closely related to the quality of surgeons and pathologists. The perioperative variables might differ in different doctors. Therefore, multicenter studies are needed to confirm our results.

\section{Conclusions}

In conclusion, the current study demonstrated that RLNs $\backslash$ count was not associated with postoperative short-term complications following gastrectomy of GC. Therefore, our analysis encouraged more lymph nodes to be dissected for accurate pathologic staging.

\section{Abbreviations \\ BMI: Body mass index; CRP: C-reactive protein; ASA: American Society of Anesthesiologists; RLNs: Retrieved lymph nodes; LNR: Lymph node ratio; LODDS: Log odds of positive lymph nodes}

\section{Acknowledgements \\ The authors gratefully acknowledge all the investigators for their contributions to the trial.}

\section{Authors' contributions}

FS worked on the study design, collected the data, and drafted the manuscript. SL contributed to the study design and data collection. PS was involved in the data collection and extraction. CZ helped collect the data. WG was involved in the study design and data extraction. MW revised the manuscript. All authors have read and approved the final manuscript.

Funding

There is no funding supporting this work.

Availability of data and materials

Access to the data and the calculation method can be obtained from the authors by email (medsunfeng@163.com).

\section{Ethics approval and consent to participate}

This retrospective study was approved by the ethics committee of Nanjing Drum Tower Hospital, Medical School of Nanjing University. Due to the retrospective nature, the requirement for informed consent was waived by the IRBs from Nanjing Drum Tower Hospital, Medical School of Nanjing University.

\section{Consent for publication}

Not applicable.

\section{Competing interests}

The authors declare that they have no competing interests.

Received: 9 June 2020 Accepted: 12 August 2020

Published online: 24 August 2020

References

1. Stewart B, Wild CP: World cancer report 2014. Public Health 2019. 
2. Bray F, Ferlay J, Soerjomataram I, Siegel RL, Torre LA, Jemal A. Global cancer statistics 2018: GLOBOCAN estimates of incidence and mortality worldwide for 36 cancers in 185 countries. CA Cancer J Clin. 2018;68(6):394-424.

3. Van Cutsem E, Sagaert X, Topal B, Haustermans K, Prenen H. Gastric cancer. Lancet. 2016;388(10060):2654-64.

4. Zhang W, Zhangyuan G, Wang J, Jin K, Liu Y, Wang F, et al. Effect of lymph nodes count in node-positive gastric cancer. J Cancer. 2019;10(23):5646-53.

5. Chu X, Yang ZF. Impact on survival of the number of lymph nodes resected in patients with lymph node-negative gastric cancer. World J Surg Oncol. 2015;13:192

6. Jiang L, Yang KH, Guan QL, Zhao P, Chen Y, Tian JH. Survival and recurrence free benefits with different lymphadenectomy for resectable gastric cancer: a meta-analysis. J Surg Oncol. 2013;107(8):807-14.

7. Deng J, Yamashita $\mathrm{H}$, Seto $\mathrm{Y}$, Liang $\mathrm{H}$. Increasing the number of examined lymph nodes is a prerequisite for improvement in the accurate evaluation of overall survival of node-negative gastric cancer patients. Ann Surg Oncol. 2017;24(3):745-53

8. Amin MB, Greene FL, Edge SB, Compton CC, Gershenwald JE, Brookland RK, et al. The eighth edition AJCC cancer staging manual: continuing to build a bridge from a population-based to a more "personalized" approach to cancer staging. CA Cancer J Clin. 2017;67(2):93-9.

9. Okajima W, Komatsu S, Ichikawa D, Kosuga T, Kubota T, Okamoto K, et al. Prognostic impact of the number of retrieved lymph nodes in patients with gastric cancer. J Gastroenterol Hepatol. 2016;31(9):1566-71.

10. Deng J, Liu J, Wang W, Sun Z, Wang Z, Zhou Z, et al. Validation of clinical significance of examined lymph node count for accurate prognostic evaluation of gastric cancer for the eighth edition of the American joint committee on cancer (AJCC) TNM staging system. Chin J Cancer Res. 2018; 30(5):477-91.

11. Kim TH, Suh YS, Huh YJ, Son YG, Park JH, Yang JY, et al. The comprehensive complication index (CCI) is a more sensitive complication index than the conventional Clavien-Dindo classification in radical gastric cancer surgery. Gastric Cancer. 2018;21(1):171-81.

12. Wang J, Hassett JM, Dayton MT, Kulaylat MN. The prognostic superiority of log odds of positive lymph nodes in stage III colon cancer. J Gastrointest Surg. 2008;12(10):1790-6

13. Dindo D, Demartines N, Clavien PA. Classification of surgical complications: a new proposal with evaluation in a cohort of 6336 patients and results of a survey. Ann Surg. 2004;240(2):205-13.

14. Hirabayashi S, Kosugi S, Isobe Y, Nashimoto A, Oda I, Hayashi K, et al. Development and external validation of a nomogram for overall survival after curative resection in serosa-negative, locally advanced gastric cancer. Ann Oncol. 2014;25(6):1179-84

15. Tóth D, Bíró A, Varga Z, Török M, Árkosy P. Comparison of different lymph node staging systems in prognosis of gastric cancer: a bi-institutional study from Hungary. Chin J Cancer Res. 2017;29(4):323.

16. De Steur WO, Dikken JL, Hartgrink HH. Lymph node dissection in resectable advanced gastric cancer. Dig Surg. 2013;30(2):96-103.

17. Maruyama K, Kaminishi M, Hayashi K-I, Isobe Y, Honda I, Katai H, et al. Gastric cancer treated in 1991 in Japan: data analysis of nationwide registry. Gastric Cancer. 2006;9(2):51-66.

18. Liang $\mathrm{H}$, Deng J. Evaluation of rational extent lymphadenectomy for local advanced gastric cancer. Chin J Cancer Res. 2016;28(4):397.

19. Degiuli M, Sasako M, Ponti A, Vendrame A, Tomatis M, Mazza C, et al. Randomized clinical trial comparing survival after D1 or D2 gastrectomy for gastric cancer. Br J Surg. 2014;101(2):23-31.

20. Sano T, Coit DG, Kim HH, Roviello F, Kassab P, Wittekind C, et al. Proposal of a new stage grouping of gastric cancer for TNM classification: international gastric cancer association staging project. Gastric Cancer. 2017;20(2):217-25.

21. Zhao E, Zhou C, Chen S. Prognostic nomogram based on log odds of positive lymph nodes for gastric carcinoma patients after surgical resection. Future Oncol. 2019;15(36):4207-22.

22. Alatengbaolide, Lin D, Li Y, Xu H, Chen J, Wang B, Liu C, Lu P: Lymph node ratio is an independent prognostic factor in gastric cancer after curative resection (R0) regardless of the examined number of lymph nodes. Am J Clin Oncol 2013, 36(4):325-330.

23. Wang J, Dang P, Raut CP, Pandalai PK, Maduekwe UN, Rattner DW, et al. Comparison of a lymph node ratio-based staging system with the 7th AJCC system for gastric cancer analysis of 18,043 patients from the SEER database. Ann Surg. 2012;255(3):478-85.
24. Degiuli M, De Manzoni G, Di Leo A, 'Ugo DD, Galasso E, Marrelli D, et al. Gastric cancer: current status of lymph node dissection. World Gastroenterol. 2016;22(10):2875-93.

25. Son T, Hyung WJ, Lee JH, Kim YM, Kim HI, An JY, et al. Clinical implication of an insufficient number of examined lymph nodes after curative resection for gastric cancer. Cancer. 2012;118(19):4687-93.

26. Li Z, Ao S, Bu Z, Wu A, Wu X, Shan F, et al. Clinical study of harvesting lymph nodes with carbon nanoparticles in advanced gastric cancer: a prospective randomized trial. World J Surg Oncol. 2016;14:88.

27. Markl B, Kerwel TG, Jahnig HG, Oruzio D, Arnholdt HM, Scholer C, et al. Methylene blue-assisted lymph node dissection in colon specimens: a prospective, randomized study. Am J Clin Pathol. 2008;130(6):913-9.

28. Aoyama T, Yoshikawa T, Morita S, Shirai J, Fujikawa H, Iwasaki K, et al. Methylene blue-assisted technique for harvesting lymph nodes after radical surgery for gastric cancer: a prospective randomized phase III study. BMC Cancer. 2014;14(1):155.

29. He M, Jiang Z, Wang C, Hao Z, An J, Shen J. Diagnostic value of nearinfrared or fluorescent indocyanine green guided sentinel lymph node mapping in gastric cancer: a systematic review and meta-analysis. J Surg Oncol. 2018;118(8):1243-56.

30. Koizumi N, Harada Y, Murayama Y, Harada K, Beika M, Yamaoka Y, et al. Detection of metastatic lymph nodes using 5-aminolevulinic acid in patients with gastric cancer. Ann Surg Oncol. 2013;20(11):3541-8.

\section{Publisher's Note}

Springer Nature remains neutral with regard to jurisdictional claims in published maps and institutional affiliations.
Ready to submit your research? Choose BMC and benefit from:

- fast, convenient online submission

- thorough peer review by experienced researchers in your field

- rapid publication on acceptance

- support for research data, including large and complex data types

- gold Open Access which fosters wider collaboration and increased citations

- maximum visibility for your research: over $100 \mathrm{M}$ website views per year

At BMC, research is always in progress.

Learn more biomedcentral.com/submissions 